\title{
Reforma del Código Penal Alemán
}

En el discurso que el ex-Ministro de Justicia Dr. h.c. Fritz Neumayer pronunció, el 21 de mayo de 1957, en la Universidad de Friburgo, al recibir el grado de Doctor honoris causa, dijo, entre otras cosas, lo siguiente respecto a la gran reforma de la parte general del Código Penal Alemán:

"En el proyecto de la parte general de un futuro Código Penal, con el cual la obra de reforma ha llegado a una fase importante, la Ciencia ha tenido una parte destacada. En la Comisión citada por mí se han reunido ilustres representantes de todos los grupos que, de distintos modos. se ocupan del Derecho penal: jueces y fiscales, abogados y funcionarios ministeriales, diputados y también profesores. Siempre he considerado como la coronación de mi actividad en el Ministerio de Justicia presidir esta Comisión y poder observar y encauzar en ciena forma la fecunda disparidad y armonía entre el poder legislativo y el ejecutivo, entre la Ciencia y la próctica.

"En esta cooperación, todos los que han participado han respondido admirablemente a las tareas que les correspondieron en la obra de reforma. Esto se refiere, y no en último término, a la Ciencia del Derecho Penal, que contribuyó decisivamente a la creación de los conceptos fundamentales y que supo responder a las exigencias de la práctica nacidas de la experiencia. Estas no son meras palabras. Quizás sepáis, y con esto me fijo en la idea fundamental de nuestro proyecto, que la Gran Comisión ha proclamdo resueltamente el principio del Derecho Penal de culpabilidad que, como pienso exponer más adelante, informa todo el proyecto de la parte general. Esta proclamación no habría sido posible sin la ayuda de la Ciencia. Al decir esto no pienso sólo en el Derecho en sí sino también en la moderna Filosofía, en la Antropología y en las Ciencias Naturales cuyo desarrollo parecía privar de base todavía en el siglo pasado a un Derecho penal de culpabilidad. Hoy las cosas son distintas. No necesito entrar en detalles pues hace pocos meses que en esta Universidad el profesor Jeschek, que pertenece también a la Gran Comisión de Derecho Penal, ha dicho convincentemente, en su magnífico discurso sobre el hombre de nuestro tiempo. 
Y las reformas del Derecho penal, (1) citando elocuentes testimonios de todas las ramas pertinentes de la Ciencia, que la idea del hombre, que aun encerrado en la comunidad $y$ en la historia, en su ambiente $y$ en él mismo, es a la vez un hombre de libertad, responde al estado actual incluso de nuestros conocimientos. Permitidme añadir que esta idea del hombre es la que está viva en el pueblo, la que estará, la que tiene que estar siempre viva. El sencillo hombre del pueblo, por mucha comprensión que tenga de lo que en la Edad Media se llamaba el "pobre pecador", no se dejará jarmás disuadir de que existe el bien y el mal y de que el criminal responsable de sus acciones es un hombre malo $\mathrm{y}$ no simplemente un enfermo o un degenerado. A esta idea del hombre responde también el concepto de la propia responsabilidad $y$, por consiguiente, de la culpabilidad. Si el hombre quisiese abdicar de esta responsabilidad moral abdicaría a la vez de sí mismo. Y siendo esto así, precisamente el Derecho penal no puede prescindir del concepto de culpabilidad. Sería absurdo que el Dere cho Penal, nada menos, quisiese tratar como a un enfermo a un hombre que el pueblo considera como un malvado.

"Se han alzado voces críticas que reprochan a nuestro proyecto, basado en el Derecho penal de la culpabilidad, que ya al aparecer será anticuado. Estas voces se alzan en distintos campos. En parte, la crítica está todavía arraigada (2) en la mentalidad de las Ciencias naturales del siglo pasado y cree que el hombre puede ser reducido todavía a la fórmula idiosincrasia y ambiente. Esta crítica no sólo pasa por alto la cordura del hombre sencillo de que os he hablado y a quien el legislador tiene que escuchar lo mismo que al hombre culto, sino que no ha entendido los signos del tiempo ni ha tenido en cuenta los conocimientos de la Ciencia del siglo $\mathrm{XX}$, ni, sobre todo, ha comprendido las enseñanzas tan caramente adquiridas de dos horrendas guerras mundiales. Quien haya vivido realmente estos acontecimientos tiene que haber visto que la culpa y la pena no son $y$ no deben ser palabras vanas. ¿Quién pretendería afirmar que los desmedidos crímenes que se han cometido y que se cometerán todavía bajo gobernantes totalitarios estuvieron exentos de culpabilidad $y$ no necesitan expiación? Pero cuando esta crítica llega a decir que la Gran Comisión sosla. ya la ley fundamental y sus postulados, lo único que puedo ergüir es que nosotros hemos procurado precisamente partir de la idea del hombre en la Ley fundamental, idea que no es naturalista sino que presupone un hombre en un mundo de valores, que vive por algunos de ellos. La dignidad en el sentido del artículo 1 de la Ley fundamental no puede reclamarla para sí más que un hombre que reconoce poder ser culpable $y$ tener que responder de su culpabilidad. Quien califique esto de "patetismo de pacotilla" Y de "fantasia clasicista", no ha comprendido que sólo la apelación al hom-

(1) Cuaderno 198/199 de las publicaciones Recht und Staat, J.C.B. Mohr. Tubinga 1957.

(2) Bauer, la idea del hombre en "La nueva sociedad", 1956, y sig. 
bre responsable puede ayudarnos a encontrar el camino entre los átroces y atrozmente presentes peligros de nuestro tiempo.

"Más en serio hay que tomar a los críticos salidos de la moderna Psiquiatría que, si bien creen que hay culpabilidad $y$ que el sentimiento de la culpa y de la responsabilidad desempeña un papel indispensable para la formación del hombre, también creen, sin embargo, que escapa a la capacidad de conocimiento del hombre la posibilidad de fijar la culpa. (3) A esto tengo que decir lo siguiente: El fallo de culpabilidad del juez es un acto dentro de una comunidad humana que ayuda a confirmarla y a conformarla y que no postula validez más que para esa comunidad. El juez, hombre, no debe tener la pretensión de querer juzgar como Dios. Consciente de la insuficiencia de su fallo, debe tener, sin embargo, el valor de pronunciarlo para sus semejantes. El fallo de culpabilidad del juez no es tampoco uan apreciación basada en conceptos de ciencias naturales, sino un acto de valoración social. $E_{s}$ perfectamente posible que la culpa no pueda demostrarse en un sentido "natural", pues su concepto se sustrae a la lógica necesariamente causal y exenta de valores de las Ciencias naturales.

"Se ha criticado por último el principio normativo de nuestro proyecto en círculos que, aunque consideran también superado el naturalismo del siglo $\mathrm{XX}$, temen sin embargo la sencilla recaída en un idealismo a ultranza de la vieja escuela. (4) Considero infundado ese temor. El proyecto contempla al hombre, no como absolutamente libre, sino que ve perfectamente el fatal encadenamiento de su existencia tanto hacia afuera como hacia adentro en el sentido de la moderna Antropología, sin que por el hombre, tai como debe ser, olvide ni mucho menos al hombre tal como es. Esto queda patente en la cauta incorporación de ciertas y profundas anomalías de carácter en el ámbito de la disposición que sustituye el art. 51 del Código Penal vigente. Pero, ante todo, encuentra expresión en el ramificado sistema de disposiciones al cual prestó especial atención la Comisión y del cual os hablaré todavía.

"Así pues, cuando el proyecto proclama un Derecho Penal consecuente de culpabilidad, no cree ser anticuado ni mucho menos sino que, frente a las tendencias del siglo pasado, muchas veces operantes todavía en el mundo, cree dar el próximo paso necesario sacando las consecuencias de las enseñanzas y de los conocimientos de nuestro siglo, sin dejar de reconocer la importancia de aquellas tendencias revolucionarias y aprovechando en gran parte sus resultados. Esto no es un camino hacia atrás, pues el Derecho penal de culpabilidad del proyecto se diferencia claramente del que podría llamarse Derecho Penal clásico. Por otra parte, precisamente una renovación del Derecho Penal no puede significar que se quiera derrocar

(3) Cfr. especialmente Kurt Schneider La apreciación de la responsabilidad, $2^{\alpha}$ edi-ción, 1953.

(4) Dombois, El hombre y la pena. Luther-Verlag, Witten, 1957 
radicalmente lo tradicional. En el proceso de un fenómeno tan viejo como la pena no puede tratarse sinó de una evolución, no de una revolución.

"El Derecho Penal de culpabilidad en el sentido del proyecto no significa sólo que no debe imponerse pena sin culpa sino que la pena no debe exceder la medida de la culpa. Esto tiene importancia en un doble sentido. Por una parte se rechaza con ello el antiguo Derecho Penal del resultado (Erfolgsstrafrecht) que hasta 1953 había dejado claras huellas en el Código penal con los llamados delitos calificados por el resultado (erfolgsqualifizierten Delikten). El nuevo proyecto exige además que en la aplicación de la pena deben considerarse como agravantes los efectos culpables, es decir recriminables de un hecho. Lo que desde luego no exige el proyecto es que la pena no deba ser inferior al grado de culpabilidad.

"Aquí nos encontraríamos, según nos indica la problemática del intento y de la imprudencia, con una desorbitación del principio de culpabilidad, incompatible con nuestro concepto del Derecho. Querer castigar la imprudencia aun cuando no se hayan ocasionado daños, contradire los postulados de un sano régimen penal. Por esto el proyecto parte del hecho de que, si bien la pena no debe exceder el grado de culpabilidad, sin embargo, en ciertos casos debe ser inferior, por ejemplo cuando la pena adecuada a la culpa se opone a la reintegración del autor y una pena menor no vulnera la necesidad de expiación.

"Aquí se ve ya que el proyecto concede perfecto valor a lo que hoy se llama "reasociación" del cutor. Pero no permite -y este es el segundo aspecto del Derecho Penal de culpabilidad- que por eso se traspone la pena adecuada a la culpa, pues esto significaría un falseamiento del concepto de la pena que, sustraída a la relación con la culpa, se convertiría en pena de finalidad (Zweckstrafe) y se rebajaría en el fondo hasta convertirse en una simple medida. La pena adecuada a la culpa no debe traspasarse para la simple intimidación de tercero porque de ese modo el autor queda degradado a simple instrumento para influir sobre otro.

"Si la necesidad de proteger a la colectividad frente al autor peligroso no puede satisfacerse, o si la readaptación del autor exige una mayor acción sobre él, esto no puede efectuarse por medio de la pena sinó con medidas de corrección $y$ seguridad. Por esto el proyecto se mantiene en el llamado sistema de vía doble del Código Penal vigente. Este sistema quedó oscuro por el hecho de que el art. 20a vigente permite castigar más gravemente al delincuente habitual peligroso, sea o no culpable de su peligrosidad. En el proyecto no existe ya esa disposición. En su lugar, y perfectamente de acuerdo con el Derecho penal de culpabilidad, prevé una agravación general de pena del reincidente cuando incurre en una mayor recriminación de culpabilidad porque no le han servido de prevención las condenas anteriores. De este modo queda legalmente concretado el concepto difícilmente comprensible de culpabilidod de conducto.

"Una consecuencia mediata del Derecho penal de culpabilidad es que el proyecto se niegue a desistir de la antigua distinción entre autoría, inducción y complicidad en nombre de un concepto general y único de autor que no permite distinguir ya en la ley las formas del hecho y el correspondiente 
grado de culpabilidad y que, por consiguiente, se adapta mejor a un Derecho Penal orientado hacia el autor y el trato que le conviene. Al mismo espíritu responde el proyecto cuando, en el caso de varios hechos, insiste en que el juez no imponga de antemano una pena uniforme adaptada a la personalidad del autor sinó penas aisladas que respondan a la culpabilidad de éste. en los distintos casos y se acumulen luego en una pena total.

"Consecuencia también del Derecho penal de responsabilidad es que el proyecto mantenga la pena de presidio $y$. junto a la prisión, prevea el arresto penal como tercera forma de pena privativa de libertad. Para un De. recho penal orientado exclusivamente hacia determinados fines, especialmente hacia la reintegración del autor a la comunidad, sería quizá recomendable fundir las formas tradicionales de penas privativas de libertad en una pena uniforme. Para el Derecho penal de culpabilidad que ve en la pena un juicio de antivalor moral sobre la culpabilidad del autor, es una necesidad graduar ese juicio según la gravedad del hecho y de la culpa y expresar esa graduación en las diferentes denominaciones de los hechos penales y en la aplicación de las distintas clases de penas. Un asesinato y unas lesiones culposas son, por su contenido de antijuridicidad y de culpa, hechos tan diferentes que la diferencia tiene que expresarse en las distintas denominaciones del hecho y de la clase de pena. Por esto el proyecto mantiene la diferencia entre "Verbrechen" (delito grave) y "Vergehen". (delito leve), mientras que considera como prescindibles los "Uebertretungen" (infracciones), todavía exisientes en el Derecho vigente, una vez que el derecho penal administrativo ha eliminado del Derecho penal las infracciones no criminales. Cuando las "Uebertretungen" tengan un contenido criminal de antijuridicidad podrán incorporarse al grupo de los delitos leves. En cambio el proyecto cree deber mantener las tres clases de penas negativas de libertad, a saber. el presidio para los delitos graves y la prisión y el arresto penal para los delitos leves.

"Cierto es que el proyecto parte del hecho de que el agravado juicio de antivalor que radica en la imposición de presidio, que dificulta al autor la vuelta a la comunidad, aunque parece imprescindible, máxime habiéndose abolido en la ley fundamental la pena de muerte, debería quedar limitada para los hechos gravísimos. Así pues, el proyecto reconoce muchos menos "Verbrechen", es decir delitos amenazados con presidio, que el Derecho vigente. En virtud de la limitación a hechos gravísimos, la pena temporal de presidio no debe empezar hasta los dos años y tener un límite máximo de 20 años. El proyecto se opone a la creación de una "custodia honesta" para reos por convicción porque podría tener consecuencias serias para la gravedad de la amenaza de pena $y$ debilitar el juicio de anti. valor del hecho que radica en la pena. Sin embargo, este problema se abor. dará de nuevo en la segunda lectura del proyecto, una vez que en la deliberación de la ley penal militar promulgada hace poco se ha visto que no puede prescindirse en cierto sector de la reclusión como "custodia honesta".

"También sirve para la realización del Derecho penal de culpabilidad el cambio de la multa por el sistema de la expiación diaria que ha dado buen resultado hace tiempo, especialmente en los países escandinavos. Mientras 
que, hasta ahora, las multas impuestas no permitían conocer hasta qué punto su cuantía estaba determinada por la gravedad del hecho y de la culpa y hasta qué punto por las condiciones económicas del vator ni tampoco la pena suplementaria privativa de libertad permitía siempre seguras conclusiones, el sistema de la expiación diaria impone una clara distinción. En el número de expiaciones diarias se refleja claramente la gravedad del hecho y de la culpa.

"Como ya he dicho, dentro del Derecho penal de culpabilidad se puede perseguir en amplia medida la finalidad de reincorporar al autor $\alpha$ la comunidad. De este punto de vista saca el proyecto toda una serie de consecuencias. Ya he citado la restricción de la pena de presidio. A esto se añade la renuncia a las penas infamantes en el sentido antiguo a las cuales reemplazarían ciertas consecuencias secundarias en el plano civil y la posibilidad de una rehabilitación de esas consecuencias por decisión judicial. El problema de las penas cortas privativas de libertad, que fué el punto culminante de los antiguos deseo de reforma, es tratado por el proyecto desde el punto de vista de la perjudicial repercusión en la vida del autor.

"Esto es de temer cuando un autor criminalmente en peligro pierde efectivamente por la pena sus vínculos personales y está expuesto durante la expiación a contagio criminal, y el tiempo de la ejecución no es, sin em. bargo, suficiente para influir con éxito sobre él. Par otra parte, una pena corta privativa de libertad con su efecto de choque parece eficaz para un autor que se encuentra en una posición social segura y que por la simple privación de libertad puede entrar en razón y comprender que tiene que responder de la injusticia cometida. Aquí hay que tener en cuenta el hecho de que el tipo humano que se presenta ante el juez ha cambiado radicalmente desde la época de Franz von Liszt. Hoy, los delitos del tráfico representan el grupo más numeroso $\mathrm{y}$, por consiguiente, comparece ante el tribunal, en lugar del autor necesitado de reasociación, el socialmente articulado para el cual parece perfectamente idónea la corta privación de libertad. Tomando en consideración por una parte estos puntos de vista, y por otra los límites marcados por el Derecho penal de culpabilidad, el proyecto establece la relación entre la prisión y la nueva pena corta prevista, el arresto penal, concebido como pena para delitos por imprudencia sin grave culpabilidad y delitos dolosos con leve culpabilidad hasta un plazo máximo de 6 meses.

"Así como el Derecho penal de culpabilidad no significa que el grado de la pena ha de responder siempre y plenamente al de la culpa, tampoco significa que deba cumplirse toda pena impuesta. El proyecto recoge, por lo tanto, la institución judicial introducida en 1953 de suspensión de la pena para prueba, perfeccionando su reglamentación en varios aspectos. Para los condenados de los que pueda esperarse para el futuro una buena conducta incluso sin una influencia especial, el proyecto prevé contribuciones que deben servir para satisfacer la injusticia cnmetida $y$ hacen en estos casos de la institución una pena de tipo especial. Para el autor que necesite que se influya sobre él, el proyecto prevé instrucciones con las cuales el tribunal interviene en la conducta del condenado. Aquí la institución por su intimo 
carácter se aproxima a una medida de corrección. Lo mismo ocurre en el caso de suspensión de un resto de pena para prueba.

"Así pues la institución de la remisión de pena pasa al verdadero sistema de medidas a las que, como ya he dicho, el proyecto presta especial atención. Lo nuevo aquí es la creación de establecimientos especiales para autores psicópatas, cuya reclusión en sanatorios y manicomios, con arreglo al Derecho vigente, ha sido un fracaso porque los psicópatas en esos establecimientos son agentes perturbadores $\mathrm{y}$ no pueden ser tratados debidamente. Experiencias hechas en el extranjero, especialmente en Dinamarca, han demostrado que es muy posible reunir a los infractores psicópatas del derecho en establecimientos adecuados y tratarlos con métodos específicos de modo que se reduzca considerablemente su reincidencia. Entre las medidas privativas de libertad deberán conservarse el internamiento de seguridad, la casa de trabajo y el alojamiento de alcohólicos y entregados a las drogas en establecimientos de deshabituación.

"La casa del trabajo tendrá sin embargo un campo de aplicación mucho más amplio y se convertirá sencillamente en una medida para autores asociales de criminalidad menor y media. El internamiento de seguridad de. berá quedar reducido a aquellos autores que hayan cumplido 25 años. Esto hace posible que el proyecto cree, con el llamado depósito preventivo, una medida completamente nueva para aquellos autores que están en peligro de convertirse en delincuentes por predisposición. También aquí se basa en gran parte el proyecto en investigaciones y experiencias del extranjero, sobre todo de los Estados Unidos, de Suiza, y de Inglaterra. Con este depósito preventivo, que debe ser un último y enérgico intento de educación, interviene al mismo tiempo el proyecto radicalmente en el Derecho penal de menores, pues la medida debe ser ya posible cuando el autor comete el hecho causante después de cumplidos los 16 años. De este modo el depósito preventivo se convierte en la medida más importante para los reincidentes jóvenes y después delincuentes por predisposición, que por experiencia se sabe que empiezan su carrera criminal generalmente muy jóvenes y que, según los últimos resultados de la Ciencia, puede conocérselos prematuramente con cierta seguridad. Hasta ahora ha sido difícil influir con éxito sobre este grupo de autores por la ruptura entre el Derecho penal de menores y el de adultos. Del depósito preventivo espera la Comisión hacer frente oportunamente, y por lo tanto con éxito, a la delincuencia por predisposición y $\alpha$ la habitual, tan peligrosas para la sociedad.

"En el ámbito de las medidas sin privación de libertad, el proyecto prevé importantes innovaciones junto a las instituciones ya existentes para la corrección, como la prohibición del ejercicio profesional y la retirada del permiso de conducción. Lo principal aquí no es la expulsión de extranjeros del territorio federal con lo cual el proyecto se basa en el Derecho anterior. La nueva medida de la que la Comisión se promete un gran efecto práctico es la llamada inspección de seguridad que casi nada tiene de común con la inspección policial del Derecho vigente, casi sin importancia. Su idea fun. damental es la de no dejar sin guía ni inspección al delincuente peligroso cun cuando esté en libertad. 
" $\AA$ esta inspección deberán estar sometidos, por una parte, los reincidentes $y$ aquellos autores que han cumplido una pena privativa de libertad de 2 años por lo menos sin que se les haya concedido suspensión del resto de la pena para prueba, y por otra, la inspección de seguridad está concebida para aquellos autores a los cuales se les ha impuesto ya el internamiento de sequridad o el depósito preventivo habiéndoseles concedido suspensión de ejecución porque la inspección en libertad promete ya un éxito de reasociación. La medida se aplica también cuando los condenados han sido prematuramente liberados del internamiento de seguridad o del depósito preventivo. Lo esencial de la inspección de seguridad es que el tribunal no da a los condenados instrucciones con las cuales se interfiere profundamente en ocasiones en su vida, sinó que, por regla general, los somete a una autoridad de inspección que generalmente será un auxiliar para la prueba, pero que para autores que no parezcan accesibles a la influencia de ese auxiliar puede ser también una autoridad de vigilancia, especialmente una sección de la policía con funcionarios debidamente preparados. La inspección de seguridad dura 2 años como mínimo y 5 años como máximo.

"Lo extenso de la materia me impide ahondar en más detalles. Ante todo tengo que renunciar a entrar en la parte dogmática del proyecto que me creo en el deber de decir que ha sido profundamente elaborada por la Comisión. Pero esta parte interesa más al especialista que al público para el cual tienen importancia ante todo las propuestas de política criminal. $\bar{A}$ mi juicio, el proyecto, con su perfeccionado sistema de penas y con el sistema de medidas de corrección y de seguridad, mucho más completo que el del Derecho vigente, y al mismo tiempo mucho más elástico, dará al juez posibilidades para condenar a cada autor según el grado de su culpabilidad y devolver al mismo tiempo a la sociedad al autor en peligro y proteger a ésta del peligroso. Para esto será preciso que el juez disponga en gran escala de medidas de corrección y de seguridad y haga resueltamente uso de ellas cuando la ley lo permita.

"Y con esto llego a un pensamiento que me interesa especialmente y que quiero acentuar para terminar mi exposición. El moderno legislador penal pone a disposición del juez, respondiendo a las exigencias de la moderna política criminal, un múltiple y ramificado sistema de posibilidades de reacción, entre ellas unas que parecen graves y tajantes para el infractor del derecho y otras en cambio que, como por ejemplo la suspensión de la pena para prueba, pueden parecer débiles si se las considera superficialmente. Sería un funesto error creer que el centro de gravedad de la reforma del Derecho penal radica en esas reacciones "débiles" y sería de un efecto fatal que los tribunales hiciesen uso de las "débiles" posibilidades de reacción y nó de las fuertes y tajantes. Una ley penal moderna exige del juez que indague detenidamente los motivos del autor $y$ se esfuerce por descubrir su personalidad. Pero sería funesto creer el principio que dice: "Comprender es perdonar". Para el juez debe regir más bien éste otro: 
"Comprender es encontrar la respuesta verdadera, es decir la justa". Esa respuesta será muchas veces severa y dura. Las cifras de nuestra estadística criminal no hablan un lenguaje tranquilizador. Uno de las principales fines de la reforma del Derecho penal es el de corregir esas cifras. Llovar a cabo esa reforma después de que los mejores cerebros del Derecho penal se han esforzado inútilmente, durante más de 50 años, por conseguirla: requiere valor y decisión y no sólo del legislador y de sus auxiliares sinó ante todo de los jueces que tienen que hacer de la nueva ley un instrumento eficaz y vivo. Permitidme pues recoger unas palabras de Gustav Radbruch, que el profesor Würtenberger puso al final de su trabajo, sugestivo y rico de pensamiento sobre la situación espiritual de la Ciencia penal alemana:

"Valor para la decisión: sólo eso es vida". 